\title{
Woronoff Ring in Deficiency of Interleukin-36 Receptor Antagonist (DITRA)
}

\author{
Daniel Morgado-Carrasco, ${ }^{1}$ Sebastian Podlipnik, ${ }^{1}$ José M. Mascaró, Jr ${ }^{1}$
}

1 Department of Dermatology, Hospital Clínic de Barcelona, Universitat de Barcelona, Spain

Keywords: Woronoff ring, psoriasis, DITRA, deficiency of interleukin-36 receptor antagonist, anakinra

Citation: Morgado-Carrasco D, Podlipnik S, Mascaró JM Jr. Woronoff ring in deficiency of interleukin-36 receptor antagonist (DITRA). Dermatol Pract Concept. 2020;10(1):e2020008. DOI: https://doi.org/10.5826/dpc.1001a08

Accepted: September 5, 2020; Published: December 31, 2019

Copyright: (02019 Morgado-Carrasco et al. This is an open-access article distributed under the terms of the Creative Commons Attribution License, which permits unrestricted use, distribution, and reproduction in any medium, provided the original author and source are credited.

Funding: None.

Competing interests: The authors have no conflicts of interest to disclose.

Authorship: All authors have contributed significantly to this publication.

Corresponding author: José M. Mascaró, Jr, MD, Department of Dermatology, Hospital Clínic de Barcelona, Barcelona, Spain. Email: josemanuel.mascaro@gmail.com

\section{Case Presentation}

A 54-year-old-man diagnosed with a deficiency of interleukin-36 receptor antagonist (DITRA) under anti-interleukin-1 therapy with anakinra (described elsewhere [1]) presented with an erythrodermic pustular psoriasis 5 months after suspension of his biological treatment (Figure 1A). Anakinra and topical corticoids were then initiated. Three days later, a halo of nonreddened skin circumscribing an erythematous pustular plaque was observed on his right side (Figure 1B). The patient showed a complete clinical response in the following weeks.

\section{Teaching Point}

DITRA is an autoinflammatory disorder caused by mutations in the ILRN36 gene, characterized by abrupt-onset episodes of generalized pustular psoriasis, fever, and systemic
Figure 1. Woronoff ring in deficiency of interleukin-36 receptor antagonist (DITRA). (A) Widespread erythematous and pustular rash on the trunk. (B) Halo of nonreddened skin circumscribing an erythematous pustular plaque on the right side (3 days after initiating anakinra and topical corticosteroids).

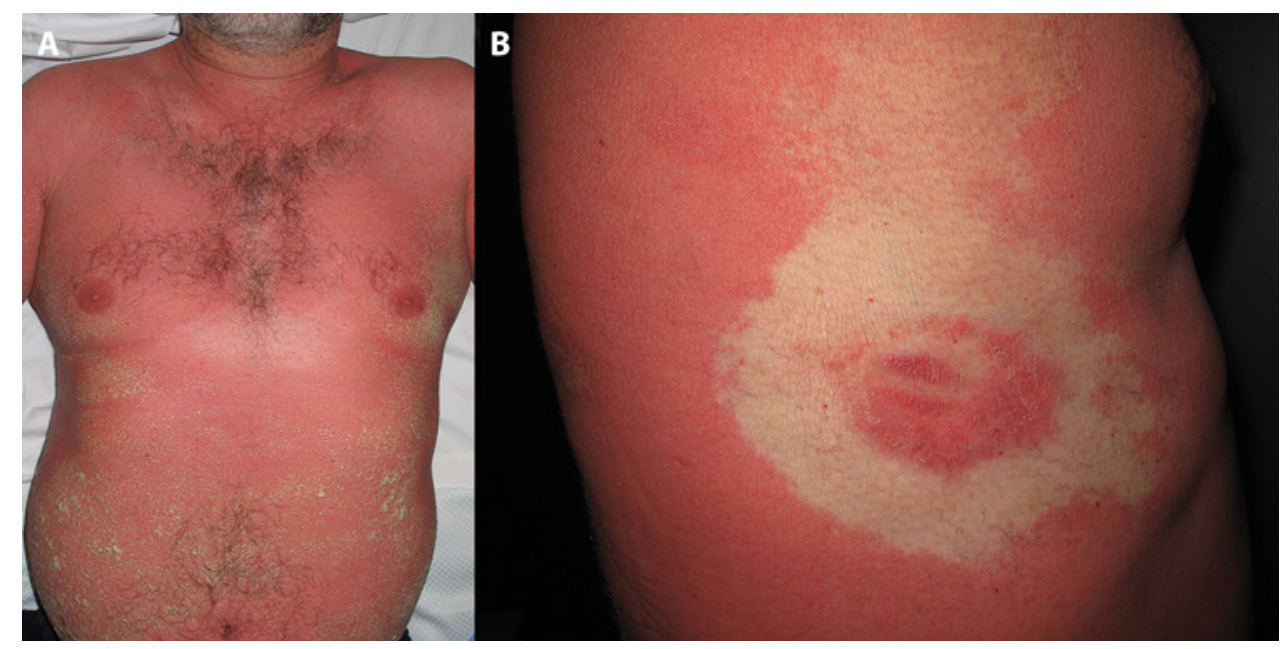


involvement. The Woronoff ring is an underrecognized sign of psoriasis, a halo of nonerythematous skin surrounding psoriatic plaques. Its pathogenesis is not fully understood; a relative deficiency of prostaglandins and endoglin has been reported. The Woronoff ring can occur after topical corticoid or tar treatment, fumaric acid esters, phototherapy, biological therapy [2], or even in untreated psoriasis.

\section{References}

1. Podlipnik S, Morgado-Carrasco D, Fustà-Novell X, et al. Dynamics of plasma cytokines in a patient with deficiency of interleukin-36 receptor antagonist successfully treated with anakinra. $\mathrm{Br} J \mathrm{Der}$ matol. 2018;178(4):e258-e260.

2. Park KK, Swan JW, Eilers D, Tung R, Koo J. Woronoff ring associated with adalimumab therapy for psoriasis. Cutis. 2014;93(2):e1-e2. 